\title{
Developing a local framework for quality in an online learning environment: a case study
}

\author{
R. McDougall' ${ }^{1}$, M. Flanders ${ }^{2}$, R. Buchanan ${ }^{3}$ and S. Lindsay ${ }^{4}$ \\ ${ }^{1,2,4}$ School of Mathematical and Decision Sciences, Central Queensland University \\ ${ }^{3}$ School of Computing and Information Systems, Central Queensland University
}

\begin{abstract}
This paper describes a quality framework for the development of a set of online learning resources, namely worked examples with audio enhancement and simulations, used to improve the offering of a level one business mathematics course at Central Queensland University. The framework centres around five criteria that emerged as the resources were developed. They were a primary reference determining the quality of the learning environment created.
\end{abstract}

Key words: quality system, online learning, mathematics, audio enhancement, simulation

\section{INTRODUCTION}

Central Queensland University has adopted the very broad 'fitness for purpose' qualification in discussions about quality teaching and learning. While various institutions in the higher education sector develop distinct yet comparable expressions for this dimension of academic work, all definitions will need to recognise the influence of the local institutional context. That is, there is no one set of quality practices that can be developed across the Australian education landscape because of the different constraints brought to bear on the term 'quality'. Despite the problematic nature of the definition of quality in higher education, there is clearly enough common ground to make discussions worthwhile.

This paper describes a quality framework for the development of a set of online learning resources, namely worked examples with audio enhancement and simulations, used to improve the offering of the course Quantitative Methods A (QMA), a level one business mathematics course at Central

The original version of this chapter was revised: The copyright line was incorrect. This has been corrected. The Erratum to this chapter is available at DOI: 10.1007/978-0-387-35700-3_33 
Queensland University. The framework centres around five criteria that emerged as the resources were developed. They were a primary reference determining the quality of the learning environment created. These criteria are by no means exhaustive, nor are they proposed on the basis that they are congruent with any particular theoretical approach that predicates the value of online learning resources. Rather they are a consequence of the experiential and innovative work that emerged from a university-funded project to increase the current range of online learning opportunities available to students, in particular distance education students.

In line with a general push to implement and apply online technology, and promote such an initiative in terms of quality, a pilot WebCT site (2001) for QMA was developed with the support of the University's Multimedia Design Centre. This site is now linked to the current term course website and provides enrolled students with an opportunity to experiment with an electronic version of the study guide and the two learning resources that are the subject of this paper.

\section{THE EMERGING CRITERIA}

Those familiar with the WebCT environment will be aware that curriculum developers are afforded the opportunity to expand this online learning application to incorporate a number of curriculum components to whatever level of complexity and innovation technology will allow. As part of the learning resources offered to students, the development team chose to concentrate initially on the completion of a set of worked examples with audio enhancement, and a number of simple mathematical simulations. Throughout the development phase, attention was focused on what students would see and how they would work with and learn from the final product.

As a result, five generic criteria emerged on which to base the assessment of the quality of the mathematical learning resources for student use. This case study supports Diana Laurillard's appeal that 'we should be building a body of knowledge of how best to use learning media and creating a teaching profession that knows what it is doing and why' (Laurillard, 2002, p.6).

The criteria developed are that the online learning resources should:

- attempt to recreate for distance students more of the face-to-face learning environment available to internal students,

- be designed to ensure that the learning activity is as closely connected to the unfolding solution as possible,

- offer a learning style that is closely aligned with those familiar to the student, 
- be simple and robust in their construction and implementation and

- be easy to replicate.

These themes are now expanded upon in terms of their application to the online resources developed.

\subsection{Recreating more of the face-to-face experience}

Online learning resources should attempt to recreate for distance students more of the face-to-face learning environment available to internal students. Accepting and working from the perspective of the 'deficit model' (Walker, 1993, p.29), the authors sought to find substitutes for the face-to-face environment and contend that the online resources allow for a better representation of the human element than that created through print-based processes alone.

In its best form, the mathematics tutorial is a rich learning environment for internal students. It includes a well-paced demonstration of the solution to key examples which illuminates important features, justifies the sequencing of the mathematical process and makes students wary of the pitfalls as they arise. The in-class tutorial not only creates an environment for student-student and student-teacher discussion but caters for differing learning styles. This 'community of practice' as referred to by Goos, Galbraith and Renshaw (1994), encourages discussion at all levels, individual reflection and assists students in decoding the formal knowledge of the mathematical discipline as it is presented. It is proposed that no matter what the learning environment, these benefits of the time-honoured mathematics tutorial should be recreated to the fullest extent possible.

To recreate partially the atmosphere of mediation by the teacher (Laurillard, 2002), the worked examples with audio enhancement have a well-paced commentary and a head-and-shoulders photograph of the person providing the commentary. The user can then hear and see the person with whom they are working and learning. The in-class demonstration of a developing solution is replicated in a series of distinct learner regulated steps.

The simulations enable the explanation of relatively complex mathematical processes to be demonstrated in the same way as that in the internal class - beginning with a blank workspace and adding to it as the information available in the problem is incorporated into the mathematical model being used to solve it. In selecting the mathematical concepts to be investigated through the use of simulations, priority was given to those concepts where the solution to a problem is multilayered in its explanation, 
like matrix multiplication and the graphical approach to linear programming. Tait (1994) proposes that for simulations to be an effective resource they require both an appropriate task and a combination of tutor and learner involvement. While the audio commentary is not yet a feature of these resources, the point is made that in their present form, the simulations are superior to the global presentations that authors of mathematics texts are often compelled to include due to the limitations of the print media (McDougall, 2002).

\subsection{Ensuring a close connection to the unfolding solution}

Mathematics textbook authors can sometimes struggle with the constraints of the printed page. There is an upper limit to how much space can be devoted to the explanation of an algorithm or mathematical process before the reading material becomes too disconnected from any included visual guides (such as illustrative diagrams, graphs and tables). These guides to the solution, whose development is an important part of the process, are often only presented in completed form (for example (Haeussler, 2002, p.309)). The online environment created in the worked examples and the simulations provides an opportunity to maintain this learning focus without compromising any of the advantages of the detailed text explanation.

In the worked examples, the focus on the activity is maintained by paced, learner-controlled, audio commentary available throughout the example. As the example develops, the ability to see previous sections of the solution minimizes the effect of scrolling. The minimisation of scrolling is deemed to be one of the important considerations for usability of a website (TAFE, 1998). Figure 1 shows the screen layout for a worked example enhanced by audio commentary. By clicking on the audio icon an explanation similar to that given in a tutorial can be heard. 

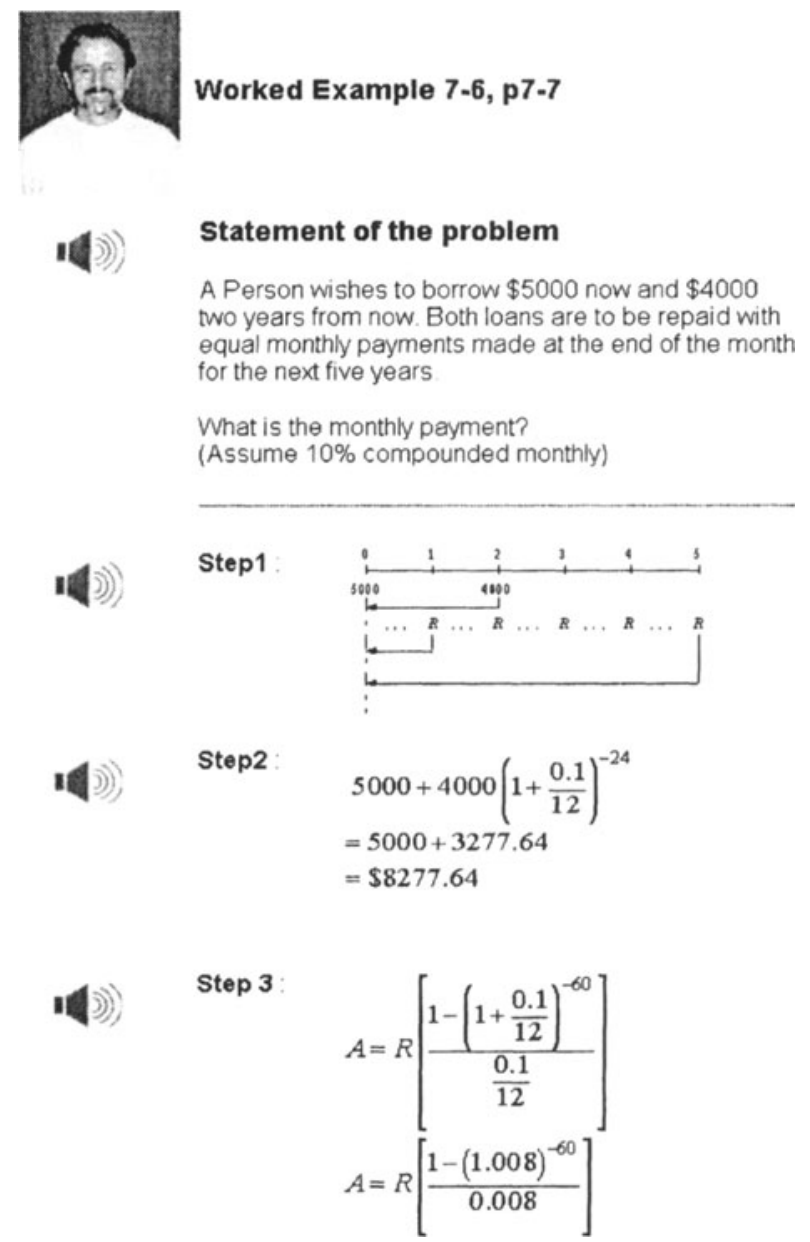

Figure 1: Screen layout for part of the solution to a worked example

The simulations are designed so that the screen has static and dynamic elements that help maintain a focus on the learning task, complementing a deconstruction and reconstruction process that allows the solution to be built up from the same starting point where students must begin (see Figure 2). The information above the separator line on the screen stays constant (although particular pieces of information may be highlighted as they are a focus for learning) while the dynamic working area below includes calculations and guiding comments. (Note that the publisher's template provided to generate this paper has meant the figure does not appear on the same page - precisely the problem that the online tools are able to transcend!) 


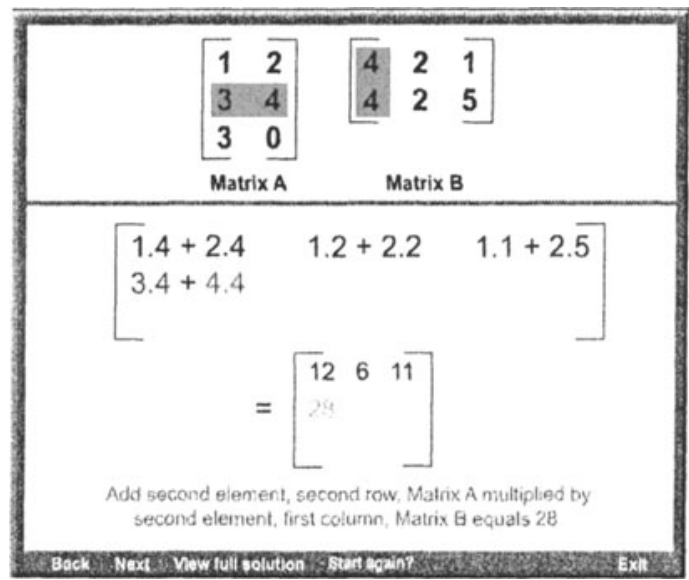

Figure 2: Screen layout for part of the simulation detailing matrix multiplication

\subsection{Securing alignment with a familiar learning style}

The criterion of incremental change to the learning style used was considered crucial to the success of the work. As staff and students make the transition to a more online and electronic environment, as much familiarity as possible in learning traditional mathematical processes needs to be maintained.

The format of the traditional worked example is very familiar to students. There is no change to the content structure of the worked examples by comparison with what they have previously experienced in the text (Haeussler, 2002) or the study guide. The enhancement of adding a paced commentary and a photograph of the person delivering the commentary takes students from a place they know well to a place where they can still be comfortable if not more so. The static areas of the screen built into the simulations allow students to rely on that information remaining constant while the dynamic areas take the solution forward.

\subsection{Creating resources that are simple and robust}

The technology driving the online resources should not compete with the knowledge needed to understand the concepts presented. A lack of consideration for what Hillman, Willis and Gunawardena call 'learnerinterface interaction' $(1994$, p.31) can result in the technology itself becoming the focus of the learning experience for students. An introduction to the worked examples and the simulations features a short list of instructions for students and the asynchronous nature of both of these resources means that students have the opportunity to play and replay them 
if they are in any doubt as to the functions of the interface options. The developers anticipated that because the resources required a minimum of plug-ins and supportive software and were reasonably platform and browser independent, they would be easier to interact with and to maintain.

The technological features of the worked examples with audio have been kept to a minimum with just one type of icon performing the one task reliably each time. The simulations have an inbuilt frame containing a number of movement options intuitively labelled and able to be actively controlled by the student. It is worth noting that the online environment is quite non-standard and ensuring functionality of resources across a number of platforms and browsers is not without its challenges.

\subsection{Developing resources that are easy to replicate}

The lack of general preparedness of academic staff for teaching in an online environment and the assumptions made that students are probably more comfortable in this space than staff are, raises significant issues at this time that must be taken into consideration. Developing the skills of academic staff so that they feel competent in an online learning environment necessitates that resources be constructed in a way that will ensure success for those less confident in the new technologies.

These locally developed resources will be of interest to others for the following reasons. The resource templates are created in a style that can be replicated in other areas of the course, other areas of mathematics and even other discipline areas unrelated to mathematics. The worked examples with audio are easily adapted to any instructional situation where there is a body of knowledge already available in printed form. More creativity is needed in adapting the simulations to fit new problem areas but the underlying technological process to create such resources will stay the same regardless of the sophistication.

\section{CONCLUDING COMMENTS}

The criteria described in this paper provide a framework through which the quality of the developed resources can be assessed. They attempt to deal with issues such as compensating for the lack of face-to-face environment, aligning the learning style needed with that already familiar to the student and creating resources that are simple, robust, easy to replicate and which ensure a close connection to the unfolding solution of the problem. 
Given the general lack of suitable mathematical online learning resources for enhancing the explanation of algorithms and other mathematical processes, these two resource examples provide a significant attempt at providing a quality learning environment for all students in this course.

\section{REFERENCES}

Goos, M., Galbraith, P. and Renshaw, P. (1994), 'Collaboration, Dialogue and Metacognition: The Mathematics Classroom as a Community of Practice' in Challenges in Mathematics Education: Constraints on Construction; Proceedings of the Seventeenth Annual Conference of the Mathematics Education Research Group of Australasia (MERGA), Lismore, July 5-8 1994, vol. 1 eds. G. Bell, B. Wright, N. Leeson and J. Geake, pp. 305313.

Haeussler, E. and Paul, R. (2002), 'Introductory Mathematical analysis for Business, Economics, and the Life and Social Sciences', $10^{\text {th }}$ edn., Prentice-Hall, NJ.

Hillman, D., Willis, D. and Gunawardena, C. (1994), 'Learner-interface interaction in distance education: an extension of contemporary models and strategies for practitioners', American Journal of Distance Education, vol. 8, no. 2, pp. 30-42.

Laurillard, D. (2002), 'Rethinking University Teaching a conversational framework for the effective use of learning technologies', $2^{\text {nd }}$ edn., Routledge Falmer, London.

McDougall, R. and Buchanan, R. (2002), 'Enhancing an Oral Tradition Online', in Higher Education Without Borders, Khon Kaen Thailand, November 25-27, 2002, to appear in the Conference Proceedings.

TAFE SA, (1998),'Pedagogical Issues: ANTA Teaching \& Learning Styles that Facilitate Online Learning', Australian National Training Authority, viewed 3 January 2003, $<$ http://dino.tafe.sa.edu.au/lsrsc/one/natproj/tal/index.htm $>$.

Tait, K. (1994), 'DISCOURSE: the design and production of simulation-based learning environments' in Design and Production of Multimedia and Simulation-based Learning Material, eds. Ton de Jong and Luigi Sarti, Kluwer Academic Publishers, Dordrecht.

Walker, R. (1993), 'Open learning and the media: transformation of education in times of change' in Reforming OPEN AND DISTANCE Education Critical Reflections from Practice, eds. T. Evans and D. Nation, Kogan Page Limited, London, pp. 15-35.

WebCT, (2001), viewed 16 January, 2003, www.webct.com. 